Research Article

\title{
Experimental Study on Strengthening and Sealing Materials and Their Application in Coal Mines
}

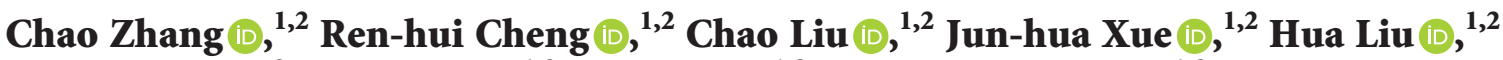 \\ Gao-han Jin $\mathbb{D}^{3}{ }^{3}$ Jie Chang $\mathbb{D}^{1,2}$ Jing Yan $\mathbb{D}^{1},{ }^{1,2}$ Xiang-zhen Zeng $\mathbb{D}^{1,2}$ \\ and Xing-long Wang $\mathbb{B D}^{1,2}$ \\ ${ }^{1}$ College of Energy Science and Engineering, Xi'an University of Science and Technology, Xi'an 710054, China \\ ${ }^{2}$ Key Laboratory of Western Mine Exploitation and Hazard Prevention of the Ministry of Education, \\ Xi'an University of Science and Technology, Xi'an 710054, China \\ ${ }^{3}$ College of Safety Science and Engineering, Xi'an University of Science and Technology, Xi'an, China
}

Correspondence should be addressed to Chao Zhang; zc@xust.edu.cn

Received 6 January 2020; Accepted 24 February 2020; Published 4 June 2020

Academic Editor: Hossein Moayedi

Copyright (C) 2020 Chao Zhang et al. This is an open access article distributed under the Creative Commons Attribution License, which permits unrestricted use, distribution, and reproduction in any medium, provided the original work is properly cited.

To solve the problem of unstable sealing in the sealing section of a gassy, soft coal seam, a seal reinforcement material for gas extraction boreholes was developed, which was mainly made of ordinary Portland cement and blended with additives such as aluminium powder, quicklime, and gypsum. Firstly, in order to obtain the necessary expansion and compressive strength of reinforcement material, key factors affecting the material properties were determined. Key factors affecting the expansion properties and compressive strength of reinforcing materials were investigated by a single-factor test. Moreover, according to the central combination (Box-Behnken) experimental principle and response surface analysis (RSA), the interactions of various factors on the expansion and compressive strength were determined, and the optimal experimental conditions were acquired. The experimental results indicated that the optimum ratio of the material was $2 \%$ for gypsum and $0.52 \%$ for aluminium powder and quicklime at the experimental temperature of $20^{\circ} \mathrm{C}$, and the ratio of water to material was 0.6. Finally, in the N1103 working face of No. 3 coal seam of Yuwu coal mine, Luan Group, China, the sealing property of the reinforcement material was validated, and the problem of hole collapse at the borehole orifice was solved (resulting in a gas concentration 2.48 times that measured before borehole reinforcement), and the gas drainage effect was enhanced.

\section{Introduction}

A large amount of gas is often associated with a coal seam and is a valuable source of clean energy, and at the same time, it can threaten the safety of mine operation [1-4]. With the continuous increase of coal mining depth in China, gas disasters are becoming more prominent [5-8]. Gas drainage, the fundamental measure to solve the gas problem, and the quality of borehole sealing can directly affect the efficiency of gas drainage and the normal operation of the whole mine [9-12]. In the process of gas extraction, the sealing of boreholes drilled is an important guarantee for high-efficiency gas extraction, and the sealing performance of sealing material restricts the efficiency of gas extraction to a great extent [13-16].

Many researchers have investigated sealing materials [17-19]. Li et al. [20] developed a new type of inorganic sealing material with good compactness and expansivity, which could improve the poor sealing effect, large air leakage, and low concentration of traditional sealing materials. However, this sealing material reduces the compressive strength of the materials while providing high expansibility; Zhai et al. [16, 21] developed a kind of flexible colloidal material suitable for drilling deformation, aiming at the shortcomings of traditional solid sealing material, to ensure the sealing effect of gas drainage during drilling. This material does not have good compressive strength and is not suitable for drilling holes in soft coal seam; Wang et al. [22] investigated the mechanism of coal seam air leakage, analysed the influences of time, active support pressure, and drainage pressure on air leakage, and proposed an active support sealing method with double expansion materials as sealing material. The material is a kind of delayed expansion 
material, and its slow solidification in the early stage makes it unable to play a good supporting role in time.

In addition, some researchers studied the optimal sealing effect of sealing materials by means of mathematical modelling and numerical simulation. Under the condition of different sealing lengths, Guan-Hua et al. [23] analysed various fracturing sealing parameters and, when combined with the Lagrange interpolation method, obtained optimised sealing parameters; Ge et al. [24] optimised the ratio of sealing materials under the optimum compressive strength and shrinkage, determined the appropriate sealing length, and verified it by field tests. Hashemi et al. [25] compared the aforementioned theoretical laboratory test data and studied the ability of hollow cylinder test data to predict the shear failure of a borehole; Erol and François [26] evaluated the performance of various grouting materials, through thermal, hydraulic, and mechanical laboratory characterisation.

Most of the published studies on borehole sealing materials have been limited to borehole seals, which belong to the sealing materials with high expansibility and low compressive strength and are not suitable for the sealing of drilled holes in high-gas loose soft coal seams. Soft coal makes a high-gas soft coal seam prone to collapse when the drill pipe exits the borehole, which makes it difficult to reach the necessary sealing depth [27]. Therefore, the slurry studied should have good expansibility, and the slurry has good compressive strength after initial setting, which can offer a good consolidation support effect on the hole sealing section and excellent permeability. In this study, higher requirements were imposed on the sealing material in view of the above problems, which requires the sealing material with high strength and microexpansion performance. Based on the previous work, in this work, the compressive strength of reinforcement material was determined by the hardness of coal seam. The single-factor experiment and multifactor experiment were used to analyse the expansion and mechanical properties of this new reinforcement material and determine the optimal ratio of the key influencing factors of the reinforcement material. To confirm the reliability of the experimental results, Yuwu coal mine was selected to verify the field effect. The results showed that the newly developed reinforcement material can solve the problem of borehole instability before borehole sealing and improve the efficiency of borehole gas drainage, which has important practical significance.

\section{Experimental Work}

2.1. Experimental Materials. The compressive strength of reinforced materials was determined as follows: the coal seams are divided into extremely hard coal seam $5.0>f>4.0$, hard coal seam $4.0>f>3.0$, medium-hard coal seam $3.0>f>1.5$, soft coal seam $1.5>f>0.8$, and extremely soft coal seam $0.8>f>0.5$ ( $f$ represents the firmness coefficient of coal and rock). The cutting machine is generally suitable for cutting the coal seam with hardness less than or equal to 4 . Therefore, the coal-rock firmness coefficient of the sealing material is $4>f>1.5$. According to equation (1), the compressive strength of the sealing material is calculated to be 15-40 MPa:

$$
f=\frac{R}{10},
$$

where $R$ is the one-way ultimate compressive strength of standard coal and rock specimens (MPa).

To meet the requirement that the compressive strength of the reinforcement material is $15 \mathrm{MPa}$ to $40 \mathrm{MPa}$, cementbased material was selected as the base material of the reinforcement material [28, 29]. Cement-based sealing materials are widely used in sealing holes for gas drainage in coal mines because of their advantages of low price, simple operation, and good applicability [30]. Based on ordinary Portland cement and other additives, a kind of sealing material for drilling reinforcement was developed. The selfdeveloped new reinforced sealing material is mainly composed of ordinary Portland cement, aluminium powder (AL), quicklime $(\mathrm{CaO})$, gypsum, and other inorganic additives. Cement is the main base material of strengthening materials, which enhances the compressive strength of materials; aluminium powder and $\mathrm{CaO}$ are mainly used as expansion agents, which can compensate for the shrinkage of the cement paste $[31,32]$; gypsum can increase the volume of cement paste and improve the overall strength [33].

The key factors affecting the expansion source of reinforcement materials are as follows:

(1) Aluminium powder: the main component of cement is silicate, which is soluble in water and weakly alkaline after hydrolysis. After adding aluminium powder into the cement, the chemical reaction of aluminium powder in the alkaline solution produces hydrogen, which will cause the volumetric expansion of the cement, compensate for the shrinkage of the cement slurry, play the role of expansion filling, and improve the sealing performance of the cement [34]. The principle of chemical expansion is as follows:

$$
\begin{aligned}
\mathrm{SiO}_{2}{ }^{2-}+\mathrm{H}_{2} \mathrm{O} & \Leftrightarrow \mathrm{HSiO}_{3}{ }^{-}+\mathrm{OH}^{-} \\
2 \mathrm{Al}+2 \mathrm{OH}^{-}+2 \mathrm{H}_{2} \mathrm{O} & =2 \mathrm{AlO}_{2}{ }^{-}+3 \mathrm{H}_{2} \uparrow
\end{aligned}
$$

(2) $\mathrm{CaO}$ : with the hydration of Cao in water, $\mathrm{Ca}(\mathrm{OH})_{2}$ is continuously generated and the lattice volume grows. In addition, a proper amount of $\mathrm{CaO}$ can be used as reactant to consume $\mathrm{Al}(\mathrm{OH})_{3}$, promoting the reaction to the right to produce hydrogen and achieve the desired expansion; too much alkaline material not only affects the early deformation performance of cement, but also causes the early deterioration of cement structure due to the segregation and cracking sensitivity induced by alkali, which also has a great impact on the early hydration and microstructure formation of cement [35]. The principle of chemical expansion is expressed as follows:

$$
2 \mathrm{Al}+\mathrm{CaO}+3 \mathrm{H}_{2} \mathrm{O}=\mathrm{Ca}\left[\mathrm{AlO}_{2}\right]_{2}+3 \mathrm{H}_{2} \uparrow
$$


(1) $\mathrm{CaO}$ dissolves in water to form $\mathrm{Ca}(\mathrm{OH})_{2}$, and the reaction is exothermic, as shown in the following equation:

$$
\mathrm{CaO}+\mathrm{H}_{2} \mathrm{O}=\mathrm{Ca}(\mathrm{OH})_{2}
$$

(2) Aluminium powder reacts with water to generate hydrogen and $\mathrm{Al}(\mathrm{OH})_{3}$ :

$$
2 \mathrm{Al}+6 \mathrm{H}_{2} \mathrm{O}=2 \mathrm{Al}(\mathrm{OH})_{3}+3 \mathrm{H}_{2} \uparrow
$$

(3) $\mathrm{Al}(\mathrm{OH})_{3}$ is an amphoteric substance, which reacts with strong bases:

$$
2 \mathrm{Al}(\mathrm{OH})_{3}+\mathrm{Ca}(\mathrm{OH})_{2}=\mathrm{Ca}\left[\mathrm{AlO}_{2}\right]_{2}+4 \mathrm{H}_{2} \mathrm{O}
$$

(3) Gypsum: the gypsum used in the experiment is gypsum dihydrate $\left(\mathrm{CaSO}_{4} \cdot 2 \mathrm{H}_{2} \mathrm{O}\right)$. Its influence on the expansion performance of sealing materials is mainly concentrated in the reaction with tricalcium aluminate $\left(\mathrm{C}_{3} \mathrm{~A}\right)$ in the cement component to produce calcium vanadate (AFt). The expansion is based on water absorption-induced swelling, and the expansion effect is produced by the increase of lattice volume, but the contribution to the expansion is generally small [36]. The chemical reaction is written as follows:

$$
\begin{aligned}
\mathrm{C}_{3} \mathrm{~A}+\mathrm{H}_{2} \mathrm{O} & \longrightarrow \mathrm{C}_{3} \mathrm{AH}_{6} \\
\mathrm{C}_{3} \mathrm{AH}_{6}+\mathrm{CaSO}_{4} \cdot 2 \mathrm{H}_{2} \mathrm{O} & \longrightarrow \mathrm{AFt}
\end{aligned}
$$

Moderate increases in gypsum content can enhance the strength of cement and strengthen and support the surrounding rock after the hole is sealed, but when the gypsum content is excessive, it continues to react with the solid state of hydrated calcium aluminate to generate high sulphur content hydrated calcium aluminate after the cement is hardened, with the volume increased by about 1.5 times, causing cement stone cracking, collapsing the hole during the second drilling operation.

2.2. Experimental Design. The single-factor experiment was used to investigate the effects of $\mathrm{A}(\mathrm{Al}), \mathrm{B}$ (gypsum), and $\mathrm{C}$ (the ratio of water to material) on the expansion properties and compressive strength of the reinforcement materials in the experiment (assuming there is no interaction between the three factors). The expansion ratio and compressive strength are the main objects of analysis, and the time of condensation was used as the secondary analysis object. Finally, the selection range of each other amount of admixture was determined. It is worth noting that, in the single-factor experiment stage, since aluminium powder and $\mathrm{CaO}$ are two reactants inducing gas expansion, they are not separable and were equally divided and repeatedly prepared as a swelling agent for these experiments. The multifactor experimental level design was determined according to the conclusions obtained from the single-factor experiment [37].

To avoid the limitation of single variable experiment and consider the influence of interaction among multiple factors, a multifactor experiment was conducted to study the significance. According to the single-factor experiment in the early stage, three main influencing factors were selected: A (Al), B (gypsum), and C (ratio of water to material). A total of 17 groups of experimental schemes were designed with three factors and three levels (Tables 1 and 2).

2.3. Performance Testing. Expansibility experiment of reinforcement materials was assessed by first, weighing a set amount of cement, and then the additive was weighed according to the experimental design table and added to the cement for uniform stirring [38]. Then, the tap water was weighed according to the ratio of water to material of the experimental design and added it to the cement, and the additive mixture was prepared in the previous step for thorough agitation. After stirring evenly, the slurry was poured into a graduated cylinder and sealed with a sealing tape. The slurry was then placed in a cement curing tank set at $20^{\circ} \mathrm{C}$ to ensure that the entire reaction was carried out under sealed, constant-temperature conditions. The initial volume of the mixed slurry was recorded as $V_{0}$, and the volume of the mixed slurry was recorded every four minutes and recorded as $V_{1}, V_{2}, V_{3}, \ldots, V_{n}$, respectively ( $V_{n}$ is the final determined value). The final expansion ratio of the reinforcing material can be calculated according to the following formula:

$$
\lambda=\frac{V_{n}-V_{0}}{V_{0}} \times 100 \%,
$$

where $\lambda$ is the expansion ratio of the reinforcing material, $V_{n}$ represents the final volume of the slurry, and $V_{0}$ is the initial volume of the slurry.

Compression strength testing of reinforcement materials was carried out $[35,39]$. To obtain the compressive strength of each component, the experimental cement slurry needed to be prepared in accordance with the amount of each component. After the slurry was thoroughly stirred, it was poured into a cylindrical mould with a diameter of $50 \mathrm{~mm}$ and a height of $100 \mathrm{~mm}$. Then, we placed the slurry on a vibrating table for compaction purposes, scraped off the excess, and smoothed the top. Next, these samples were placed in an incubator at a temperature of $20^{\circ} \mathrm{C}$. This experiment researched the compressive strength of the cement components after solidification for $48 \mathrm{~h}$. To ensure the integrity of the sample, the test block was taken out after being placed for $3 \mathrm{~h}$, the upper and lower surfaces were smoothed and the compressive strength was measured immediately. On account of the solidification time being short and the cement weak, special care must be taken during demoulding and grinding to avoid damage to the test block.

So as not to affect the smooth operation of downhole drilling, considering the possibility of field operation and the 
TABLE 1: Factors and their levels used in the Box-Behnken design.

\begin{tabular}{lcccc}
\hline Factor & Unit & & Level & \\
\hline Aluminium powder content & $\%$ & 0.43 & 0.52 & 0.68 \\
Gypsum content & $\%$ & 1 & 2 & 3 \\
Ratio of water to material & & 0.5 & 0.6 & 1 \\
\hline
\end{tabular}

TABLE 2: Experimental plans and results.

\begin{tabular}{lccccc}
\hline Class number & $\mathrm{A}$ & $\mathrm{B}$ & $\mathrm{C}$ & $\mathrm{E}$ & $\mathrm{S}$ \\
\hline 1 & 0.52 & 1.00 & 0.50 & 10.9 & 11.1 \\
2 & 0.52 & 2.00 & 0.60 & 10.5 & 10.6 \\
3 & 0.52 & 3.00 & 1.00 & 8.7 & 7.8 \\
4 & 0.52 & 1.00 & 1.00 & 7.4 & 5.7 \\
5 & 0.52 & 2.00 & 0.60 & 10.5 & 10.6 \\
6 & 0.68 & 2.00 & 1.00 & 9.6 & 5.6 \\
7 & 0.43 & 1.00 & 0.60 & 7.5 & 11.8 \\
8 & 0.68 & 1.00 & 0.60 & 12.1 & 8.2 \\
9 & 0.43 & 2.00 & 1.00 & 6.9 & 8.9 \\
10 & 0.68 & 2.00 & 0.60 & 12.4 & 8.7 \\
11 & 0.52 & 3.00 & 0.50 & 11.9 & 12.2 \\
12 & 0.43 & 2.00 & 0.50 & 9.5 & 15.6 \\
13 & 0.68 & 3.00 & 0.60 & 12.9 & 9.4 \\
14 & 0.68 & 2.00 & 0.50 & 13.8 & 10.6 \\
15 & 0.43 & 2.00 & 0.50 & 9.3 & 14.3 \\
16 & 0.52 & 1.00 & 0.60 & 9.8 & 10.1 \\
17 & 0.43 & 3.00 & 0.60 & 8.2 & 13.2 \\
\hline
\end{tabular}

$\mathrm{E}$ denotes the expansion ratio and $\mathrm{S}$ is the compressive strength.

time taken, it is necessary to strengthen the material to meet the required compressive strength within $48 \mathrm{~h}$ (above $15 \mathrm{MPa}$ ). Therefore, the compressive strength of the reinforcement material at $48 \mathrm{~h}$ was measured.

\section{Results and Discussion}

\subsection{Influence of Ingredients in Reinforcement Materials on Material Properties}

3.1.1. Effects of Aluminium Powder and Quicklime on Material Properties. The experiment determined that the aluminium powder and $\mathrm{CaO}$ doses were $0 \%, 0.43 \%, 0.52 \%$, and $0.68 \%$; the experimental temperature was $20^{\circ} \mathrm{C}$; and the ratio of water to material was 0.6 .

As shown in Figure 1(a), when the amount of aluminium powder added is $0 \%$, the final expansion ratio is $-2.3 \%$. The main reason for the shrinkage is that the pores formed by the cement in the hydration stage and the C-S-H gel (calcium silicate hydrate gel) will shrink due to the decreased moisture content during drying. As the aluminium powder content increased from $0.43 \%$ to $0.68 \%$, the expansion ratio of the reinforcing material increased from $7.2 \%$ to $10.2 \%$. As the reaction between aluminium powder and quicklime continued, the reaction began at 0 to 16 minutes, generating more gas and increasing the expansion ratio. When the experiment was carried out for 16 to $32 \mathrm{~min}$, the reactants and reaction rate gradually decreased, and the expansion ratio increased slowly. When the experiment was conducted for 32 to $48 \mathrm{~min}$, the reaction was completed and the material was stabilised. At this time, the expansion ratio did not increase, and the expansion ratio curve eventually became flat.

In Figure 1(b), the blue line represents the change of the compressive strength of the reinforced material with different aluminium powder contents at $48 \mathrm{~h}$. The red line shows the change of the initial and final setting time of the reinforced material with different aluminium powder contents (Figures 2(b) and 3(b) also show similar changes). Figure 1(b) shows that as the amount of aluminium powder increased, the initial solidification time and final solidification time of the cement material were reduced slightly [40]. This is because, upon addition of aluminium powder and quicklime, the changes in water content in the cement slurry and a small amount of $\mathrm{f}-\mathrm{CaO}$ (free calcium oxide) in the cement itself are accelerated, which accelerates the hydration and hardening of the cement, but the effect is not obvious. When the amount of aluminium powder added is $0 \%$, the compressive strength is $13.5 \mathrm{MPa}$; the amount of aluminium powder is increased from $0.43 \%$ to $0.68 \%$, and the compressive strength is reduced from $9.8 \mathrm{MPa}$ to 6.9 $\mathrm{MPa}$. This is because with the addition of aluminium powder and quicklime, bubbles remain in the cement slurry, which reduce the strength thereof. When insufficient aluminium powder is added, the expansion requirement cannot be satisfied; upon excessive addition thereof, the internal pores of the cement grow, and the compressive strength is decreased. In general, it is concluded that the cement expansion ratio was about $10 \%$, and the suitable dose of aluminium powder was about $0.52 \%$.

\subsubsection{Effect of Gypsum Content on Material Properties.} The experiment determined that the amount of gypsum added was $0 \%, 1 \%, 2 \%$, and $3 \%$; the experimental temperature was $20^{\circ} \mathrm{C}$, and the ratio of water to material was 0.6.

Figure 2(a) illustrates that gypsum content is increased from $0 \%$ to $3 \%$, the final expansion ratio of the cement slurry is increased to $1.72 \%$, and when the gypsum content is increased from $1 \%$ to $3 \%$, the three curves are similar. When the gypsum content is $1 \%$ or $2 \%$, the expansion ratio of the cement slurry is similar because the gypsum is slower to form after the gypsum is dissolved in the cement, and the solid phase remained unchanged before and after the reaction, which fundamentally limits the expansion effect.

Figure 2(b) shows that, with the increase of gypsum content, the compressive strength of cement paste gradually increases from $8.9 \mathrm{MPa}$ to $9.8 \mathrm{MPa}$; the solidification time is also gradually increased from 16 to $26 \mathrm{~min}$. It can be concluded that the amount of gypsum has little effect on the strength of the cement paste because the gypsum helps to solidify the cement slurry. Meanwhile, the gypsum also prolongs the setting time, increases the reaction time of the slurry, and provides a guarantee for the grouting time. Therefore, the choice of gypsum content is about $1 \%$ to $2 \%$.

3.1.3. Effect of the Ratio of Water to Material on Properties of Reinforcing Materials. The experiment determined that the amount of the ratio of water to material was $1,0.6$, and 0.5 ; 


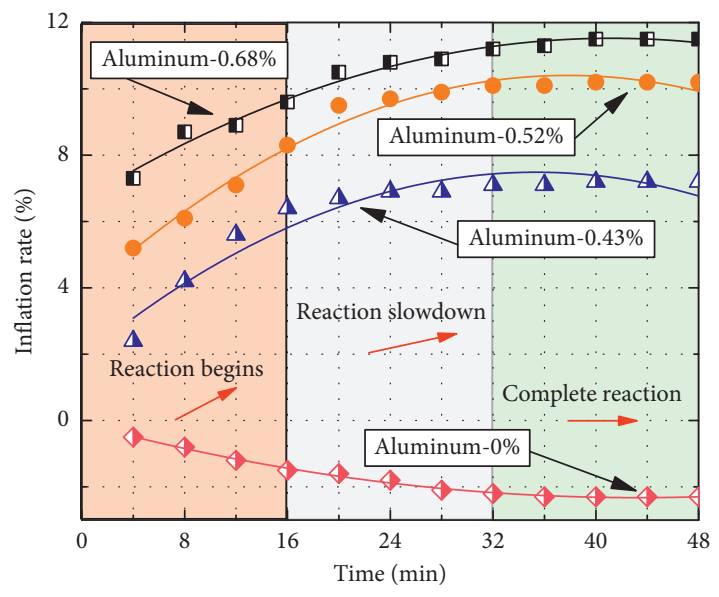

(a)

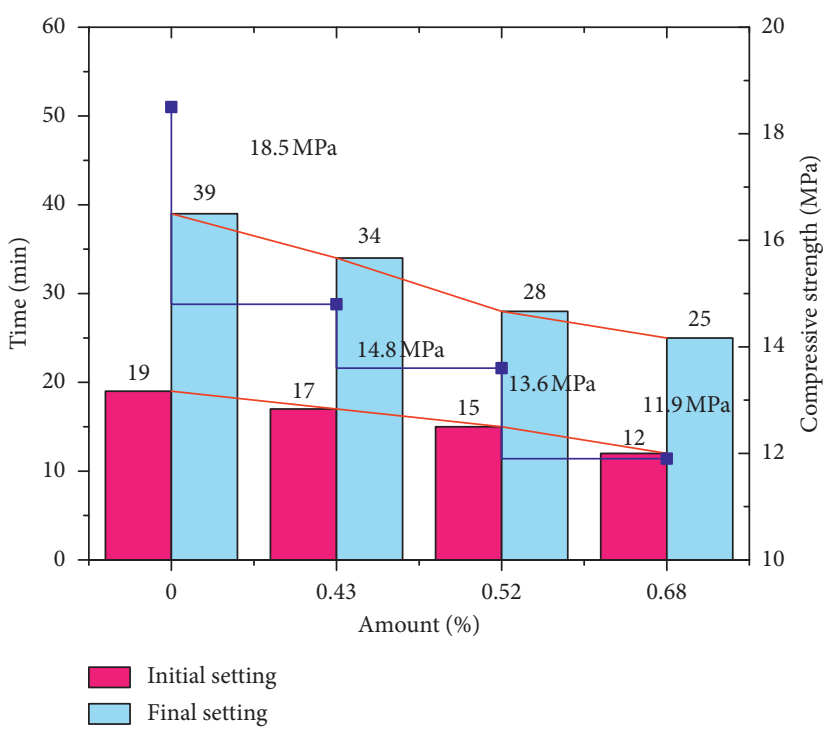

(b)

FIGURE 1: Effects of aluminium and quicklime content on material properties. (a) Effects of aluminium and quicklime content on expansion. (b) Effects of aluminium and quicklime content on solidification time and compressive strength.

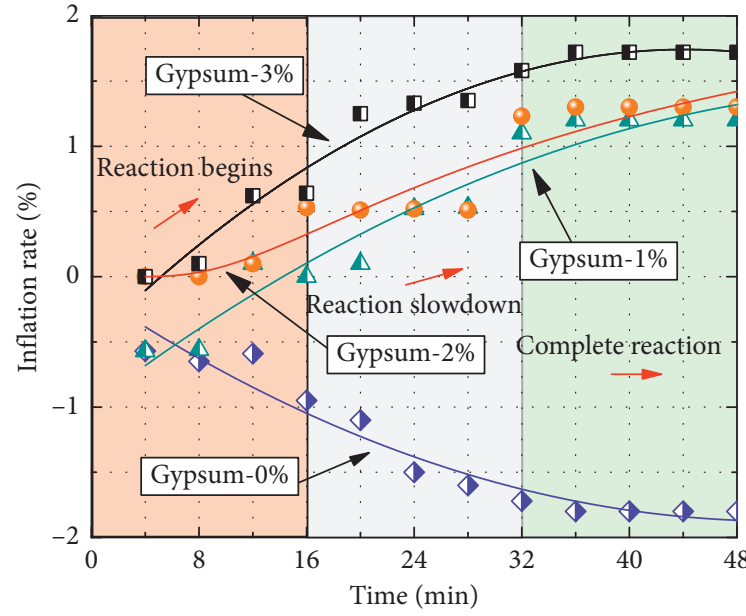

(a)

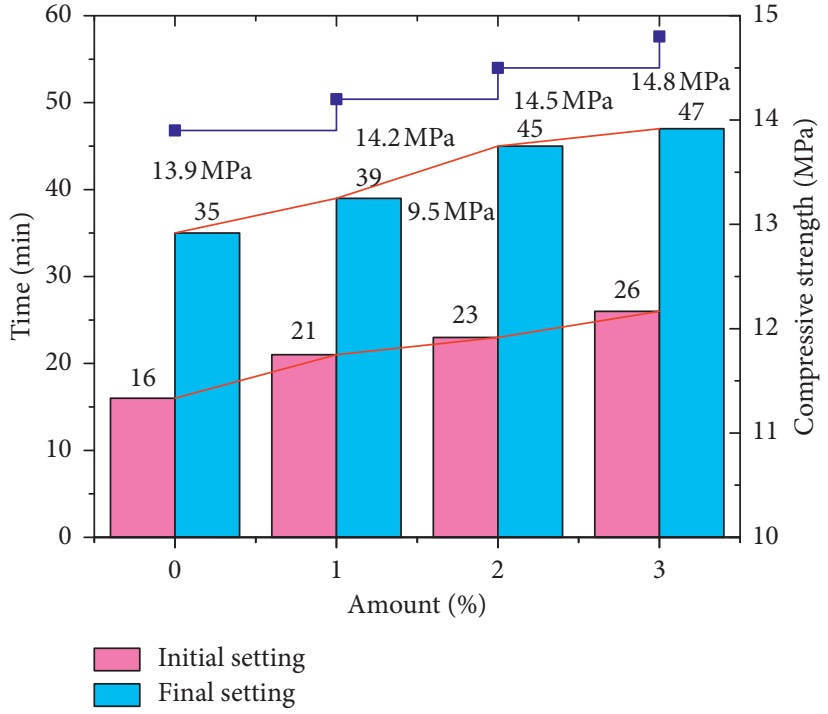

(b)

FIGURE 2: Effect of gypsum content on material properties. (a) Effect of gypsum content on expansion. (b) Effect of gypsum content on solidification time and compressive strength.

the aluminium powder and calcium oxide contents were both $0.52 \%$, the gypsum content was $2 \%$, and the experimental temperature was $20^{\circ} \mathrm{C}$.

As seen from Figure 3(a), as the ratio of water to material is reduced from 1 to 0.5 , the expansion ratio increases from $7.9 \%$ to $11.2 \%$. This is because, when the ratio of water to material is lowered, the solid volume material per unit volume of slurry increases, enhancing the effect of the expansion agent; however, if the ratio of water to material is too large, segregation will occur at the initial stage of solidification of the cement, and the pore distribution is more loose. $\mathrm{H}_{2}$ generated by the reaction of the aluminium powder and water will escape (in part), resulting in a decrease in the expansion ratio. At the beginning of the experiment from 0 to $16 \mathrm{~min}$, since the reaction had just started, the reactants were present in sufficient quantity and the reaction rate was fast; as the reaction proceeded for 16 to $32 \mathrm{~min}$, the masses of reactants were continuously reduced, resulting in a gradual slowing of the reaction rate. The reaction was substantially complete when the reaction was carried out for 32 to $48 \mathrm{~min}$; however, regardless of the ratio of water to material being $1: 1$ or $1: 2$, the final expansion 


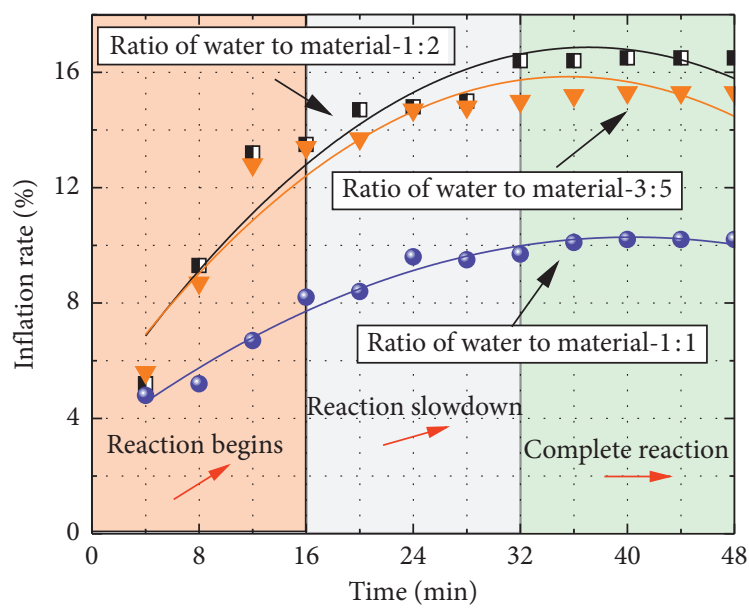

(a)

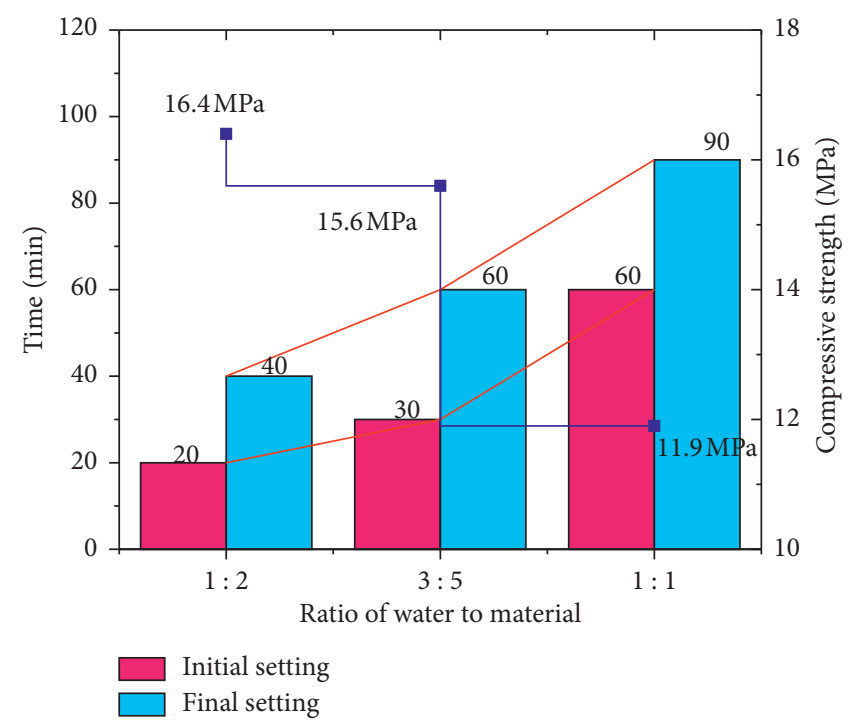

(b)

FiguRE 3: Effect of the ratio of water to material on material properties. (a) Effect of the ratio of water to material on expansion. (b) Effect of the ratio of water to material on solidification time and compressive strength.

ratio of the cement had reached more than $10 \%$, in line with our experimental requirements.

Figure 3(b) illustrates that, with the increase of the waterto-material ratio, the initial solidification time of cement slurry increases from $20 \mathrm{~min}$ to $60 \mathrm{~min}$, the final solidification time increases from $40 \mathrm{~min}$ to $90 \mathrm{~min}$, and the compressive strength decreases from 11.4 MPa to 6.9 MPa. This is because the increase in the water-to-feed ratio leads to a decrease in the cement slurry concentration, a decrease in the solid volume of the cement per unit volume, and a longer solidification time. Furthermore, the compressive strength of the cement slurry is reduced. Since the ideal value of the compressive strength of the cement paste is $10 \mathrm{MPa}$, the value of the ratio of water to material was finally determined to be between 0.5 and 0.6 .

3.2. Optimal Choice of Proportion of Components. To elucidate the effect of the interaction of three factors on the reinforcing material, a 17-group orthogonal experiment (Table 2) was designed, and the results of the experiment are described below.

3.2.1. Expansive Multifactor Analysis. As can be seen from Table 3, Design-Expert recommends the use of a quadratic model with minimal bias and better fit than other models.

Figure 4 demonstrates a normal distribution diagram of the studentised residual, which can be used to determine whether, or not, the obtained observation has an abnormal point after fitting with the model. The distribution of the residual points on the graph is almost collinear, indicating that the fitting effect of the model is more accurate and reliable.

According to the quadratic model multiple regression equation, the optimal contour lines between the respective
TABLe 3: $R^{2}$ analysis.

\begin{tabular}{|c|c|c|c|c|}
\hline Source & $\begin{array}{l}\text { Sequential } P \\
\text { value }\end{array}$ & $\begin{array}{c}\text { Adjusted } \\
R^{2}\end{array}$ & $\begin{array}{c}\text { Predicted } \\
R^{2}\end{array}$ & \\
\hline Linear & $<0.0001$ & 0.9239 & 0.8845 & \\
\hline $2 \mathrm{FI}$ & 0.4083 & 0.9250 & 0.8414 & \\
\hline Quadratic & 0.0007 & 0.9893 & 0.9500 & Suggested \\
\hline Cubic & 0.1535 & 0.9976 & & \\
\hline
\end{tabular}

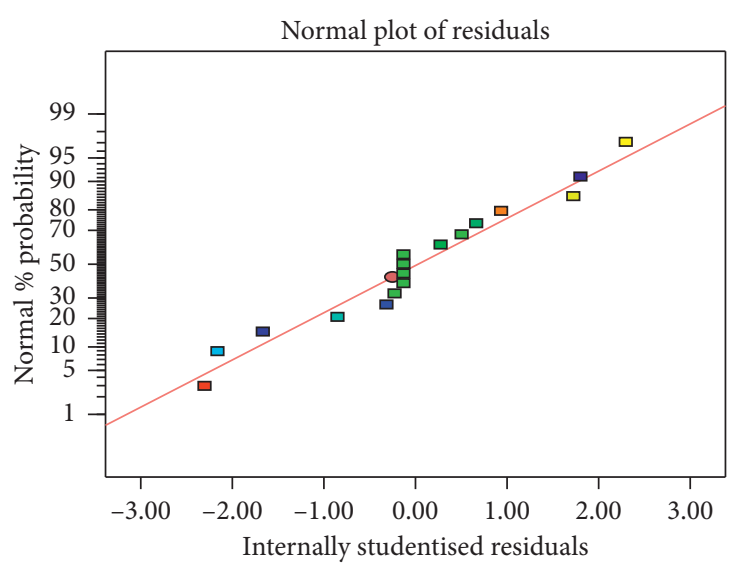

FIgURE 4: Normal probability distribution diagram of the studentised residuals.

variables and the response surfaces between the respective variables are drawn (Figures 5 and 6).

The shape and trend of contour lines can reflect the intensity and significance of the interactions between the two factors. As illustrated in Figure 5, the interaction between A (aluminium powder) and $\mathrm{C}$ (the ratio of water to material) is the most obvious. When the expansion ratio is less than $10 \%$, as the amount of aluminium powder increases 


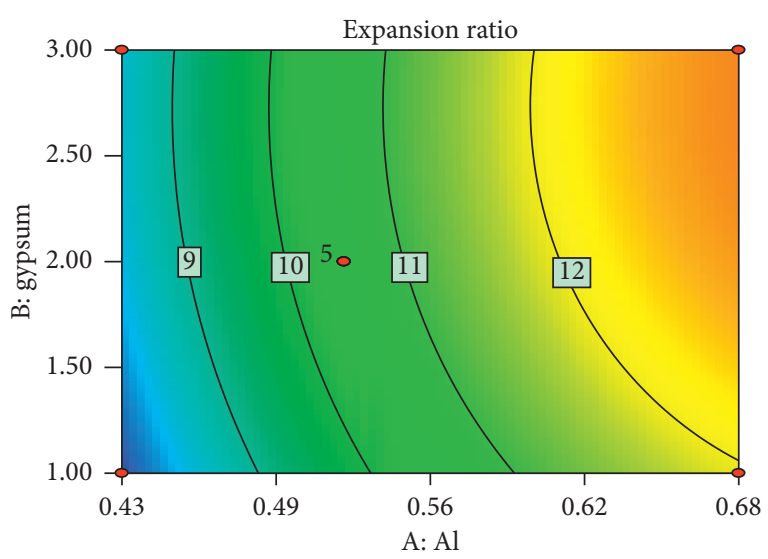

(a)

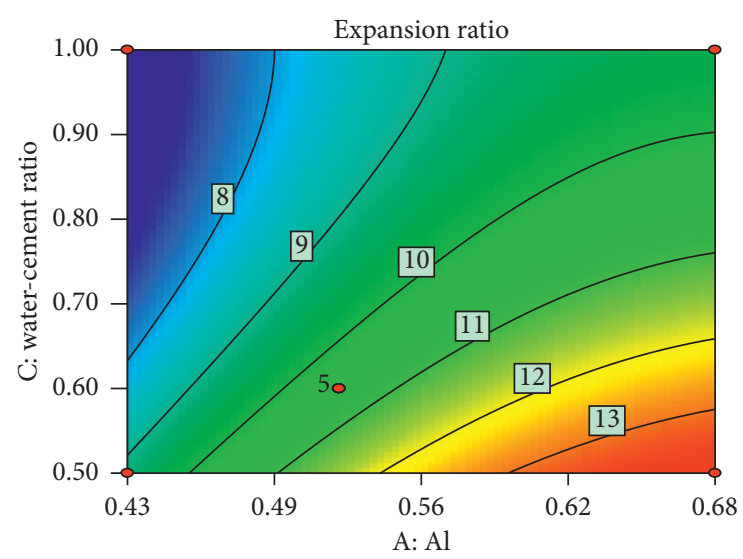

(b)

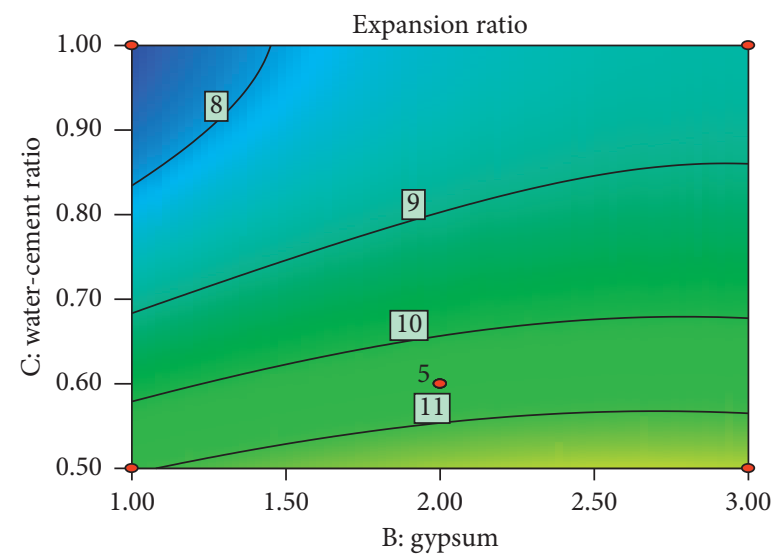

(c)

Figure 5: Optimised contours between the respective variables. (a) Optimised contour between A and B. (b) Optimised contour between A and C. (c) Optimised contour between B and C.

gradually, the ratio of water to material increases gradually. This is because the amount of aluminium powder contributes most to the expansivity. To maintain the constant expansivity, the ratio of water to material must be increased to weaken the expansibility. Secondly, when the expansion ratio is less than $10 \%$, only a small amount of aluminium powder must be added to reduce the gypsum content quickly, and when the amount of gypsum is less than $2 \%$, the results are consistent with the results of the single-factor experiment. Finally, the interaction relationship between $\mathrm{B}$ (gypsum content) and $\mathrm{C}$ (water-to-material ratio) is the worst. When the expansion ratio is fixed, the interaction contour between gypsum content and the ratio of water to material is relatively smooth, and the effect of the ratio of water to material on expansion ratio is much greater than that of gypsum. The results are consistent with the results of the single-factor experiment and ANOVA.

Figure 5 demonstrates that compared with curves $\mathrm{AB}$ and $\mathrm{BC}$, the $\mathrm{AC}$ optimisation contour changes faster and the interaction is most obvious. From Figure 6, it can be observed that the response surface of $A C$ is the steepest, followed by $A B$, and that of $B C$ is almost flat. When the expansion ratio is $10 \%$, with the increase of aluminium powder content, the gypsum content decreases rapidly, and the ratio of water to material increases slowly. With the increase of gypsum content, the increase of the ratio of water to material is almost zero. This is because aluminium powder is the main factor affecting the expansion of the reinforcing material, and the ratio of water to material only exerts a certain influence on the expansion of the material, and the influence of the gypsum on the expansivity of the solid material can be negligible.

3.2.2. Multifactor Analysis of Compressive Strength. As can be seen from Table 4, Design-Expert recommends the use of a quadratic model with minimal bias and better fit than other models.

In Table 5, the $F$-value is $57.15, P<0.0001$, indicating that the model has a high degree of fit to the data, and the experimental error is small. In the significance test, the $P$ values of the three factors $\mathrm{A}, \mathrm{B}$, and $\mathrm{C}$ are all less than 0.05 , suggesting that the three indicators are significant; the one degree term $P_{\mathrm{AB}}=0.8911, P_{\mathrm{AC}}=0.3259$, and $P_{\mathrm{BC}}=0.2528$ : the saliency order is such that $\mathrm{BC}>\mathrm{AC}>\mathrm{AB}$, and the interaction of $\mathrm{BC}$ is the most significant; the quadratic terms $P_{\mathrm{A}}^{2}=0.0086, P_{\mathrm{B}}^{2}=0.2439$, and $P_{\mathrm{C}}^{2}=0.0610$ : the saliency order is such that $\mathrm{A}^{2}>\mathrm{C}^{2}>\mathrm{B}^{2}$ and the interaction of $\mathrm{A}^{2}$ is the most significant. 


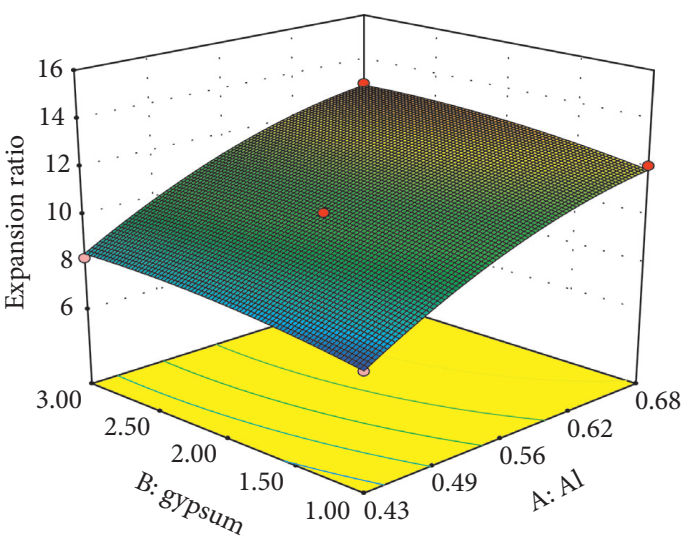

(a)

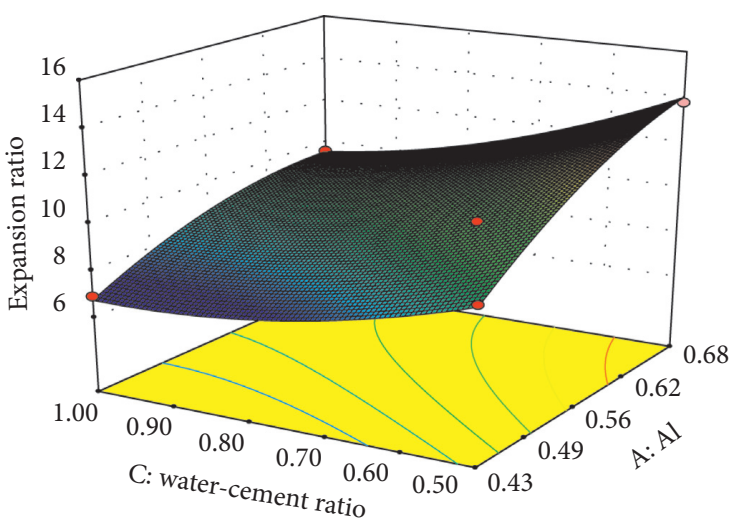

(b)

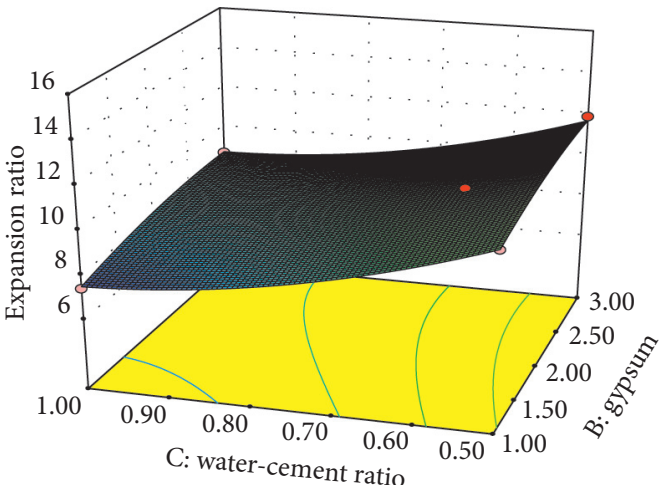

(c)

Figure 6: Response surface between the respective variables. (a) The response surfaces of A and B. (b) The response surfaces of A and C. (c) The response surfaces of $\mathrm{B}$ and $\mathrm{C}$.

TABle 4: $R^{2}$ analysis.

\begin{tabular}{lccc}
\hline Source & Sequential $P$ value & Adjusted $R^{2}$ & Predicted $R^{2}$ \\
\hline Linear & $<0.0001$ & 0.4507 & 0.9150 \\
2FI & 0.7690 & 0.3865 & 0.9008 \\
Quadratic & 0.0100 & 0.8493 & 0.9693 \\
Cubic & 0.8493 & 0.9430 & \\
\hline
\end{tabular}

TABLE 5: Response surface quadratic model and analysis of variance results.

\begin{tabular}{|c|c|c|c|c|c|c|}
\hline Source & Sum of squares & Degree of freedom & Mean square & $F$-value & $\begin{array}{l}P \text { value } \\
\text { Prob. }>F\end{array}$ & \\
\hline Model & 116.93 & 9 & 12.99 & 57.15 & $<0.0001$ & Significant \\
\hline A & 26.87 & 1 & 26.87 & 118.21 & $<0.0001$ & \\
\hline B & 3.96 & 1 & 3.96 & 17.40 & 0.0042 & \\
\hline $\mathrm{C}$ & 56.02 & 1 & 56.02 & 246.41 & $<0.0001$ & \\
\hline $\mathrm{AB}$ & $4.579 E-003$ & 1 & $4.579 E-003$ & 0.020 & 0.8911 & \\
\hline $\mathrm{AC}$ & 0.25 & 1 & 0.25 & 1.12 & 0.3259 & \\
\hline $\mathrm{BC}$ & 0.35 & 1 & 0.35 & 1.55 & 0.2528 & \\
\hline$A^{2}$ & 2.97 & 1 & 2.97 & 13.05 & 0.0086 & \\
\hline $\mathrm{B}^{2}$ & 0.37 & 1 & 0.37 & 1.62 & 0.2439 & \\
\hline $\mathrm{C}^{2}$ & 1.13 & 1 & 1.13 & 4.97 & 0.0610 & \\
\hline Residual & 1.59 & 7 & 0.23 & & & \\
\hline Lack of fit & 0.75 & 5 & 0.15 & & & \\
\hline Pure error & 0.84 & 2 & 0.42 & & & \\
\hline Cor. total & 118.52 & 16 & & & & \\
\hline
\end{tabular}




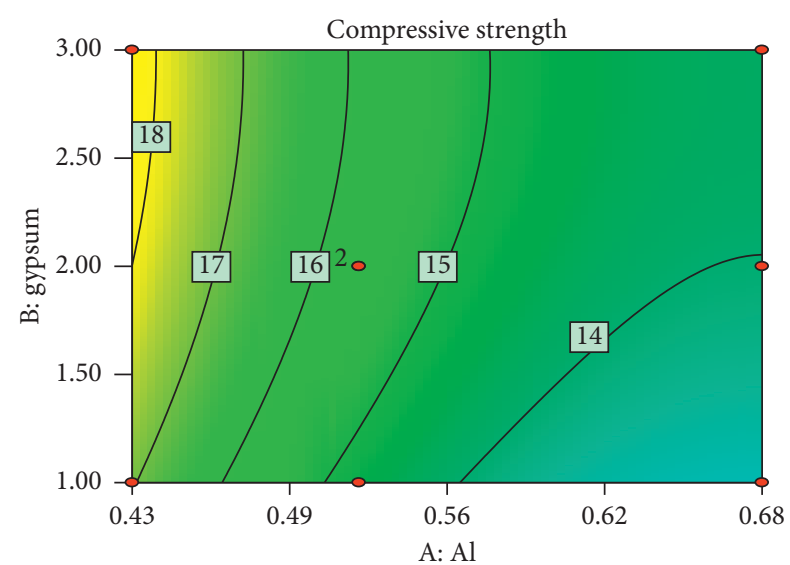

(a)

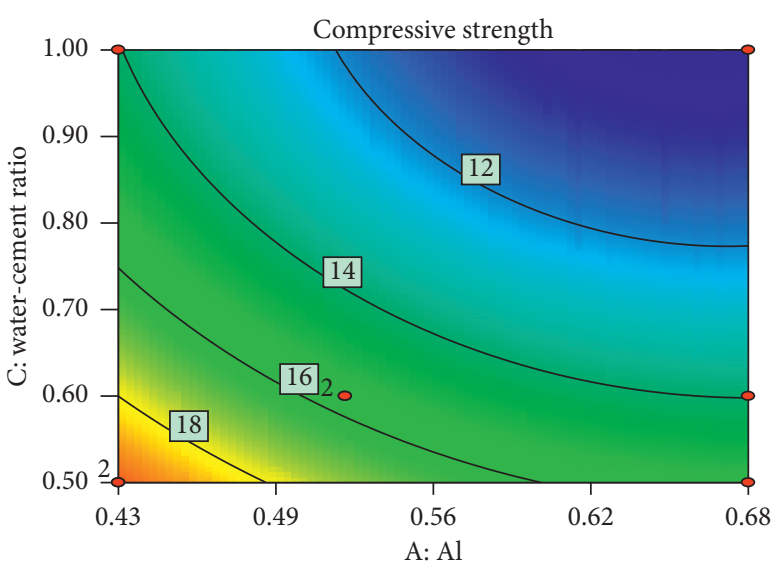

(b)

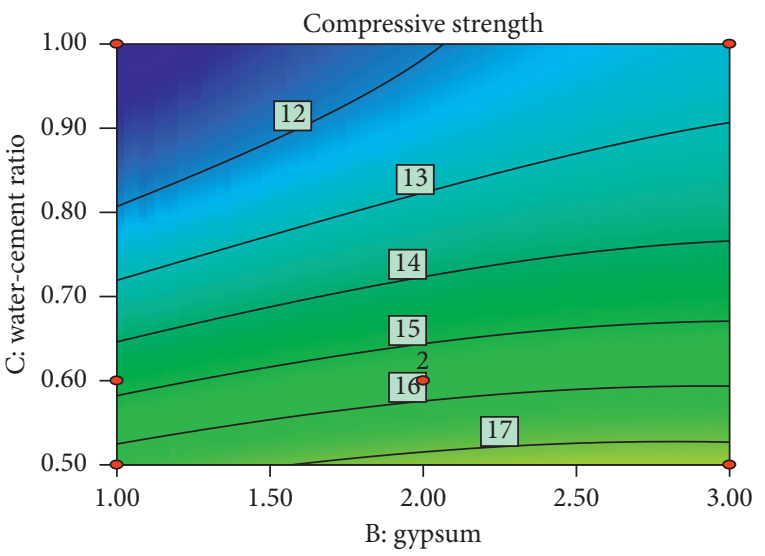

(c)

Figure 7: Optimised contours between the respective variables. (a) Optimised contour between A and B. (b) Optimised contour between A and C. (c) Optimised contour between B and C.

According to the quadratic model multiple regression equation, the optimal contours between the respective variables and the response surface between the respective variables are drawn (Figures 7 and 8).

It can be seen from Figures 7 and 8 that when the compressive strength is $15 \mathrm{MPa}$, with the increase of the amount of aluminium powder gradually, the ratio of water to material decreases rapidly, This is because the amount of aluminium powder contributes the most to the expansivity, which reduces the compressive strength of the reinforced material, and gypsum provides a certain compressive strength for the reinforced material. Secondly, the smaller the $\mathrm{C}$ (ratio of water to material), the higher the compressive strength of the material, the larger its viscosity, but the smaller ratio of water to material is not conducive to the hole sealing hole in a grouting field test. Finally, the interaction effect of B (gypsum) and C (ratio of water to material) is more obvious, and the response of gypsum and the ratio of water to material is steeper than that of the surface. The effect of the ratio of water to material is much greater than that of gypsum. The results are consistent with the results of singlefactor experiment and ANOVA.

Figure 7 illustrates that, compared with the $\mathrm{AB}$ and $\mathrm{AC}$ curves, the $\mathrm{BC}$ optimisation contour changes faster and the interaction is most obvious. From Figure 8 , it can be observed that the response surface of $\mathrm{BC}$ is the steepest, followed by $\mathrm{AC}$, and $\mathrm{AB}$ is almost flat. When the compressive strength is $15.6 \mathrm{MPa}$, as the amount of aluminium powder increases, the amount of gypsum increases rapidly, and the ratio of water to material decreases slowly. However, as the amount of gypsum increases, the ratio of water to material increases to almost zero. This is because the addition of aluminium powder can make the reinforcement material expand and the generated gas greatly reduces the strength of the reinforcing material, and the addition of gypsum enhances the strength of the reinforcement material.

\subsubsection{Optimisation and Verification of Experimental Results.} In order to further analyse and verify the experimental results, the optimised experimental scheme was obtained by Design-Expert, and then five sets of recommended experimental schemes were selected for verification.

Table 6 shows that, using the ratio recommended by Design-Expert 8.0.6 Trial, the maximum absolute error of the predicted value and the true value is only $0.1 \%$, regardless of the expansion ratio or compressive strength of the cured material, indicating that the model is relatively reliable. 


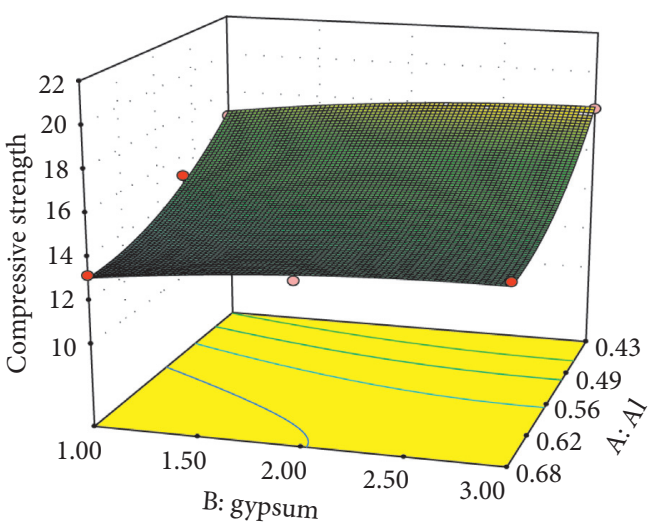

(a)

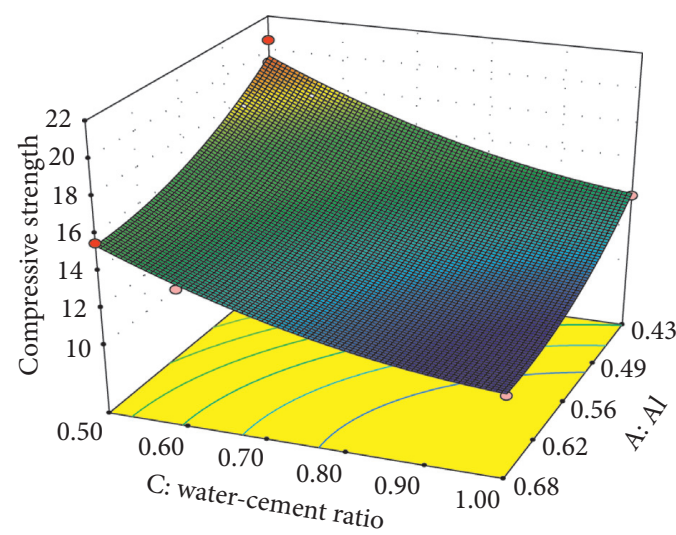

(b)

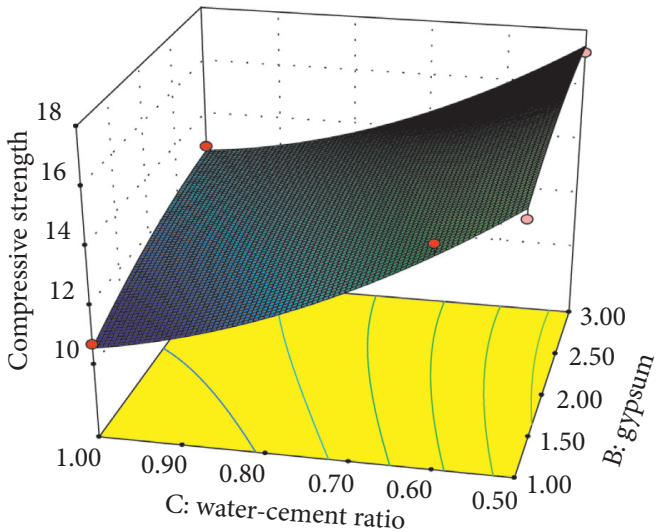

(c)

Figure 8: Response surface between the respective variables. (a) The response surfaces of A and B. (b) The response surfaces of A and C. (c) The response surfaces of B and C.

TABLE 6: Optimised ratio and result verification.

\begin{tabular}{cccccccccc}
\hline No. & $\begin{array}{c}\text { Al } \\
(\%)\end{array}$ & $\begin{array}{c}\text { Gypsum } \\
(\%)\end{array}$ & $\begin{array}{c}\text { Ratio of } \\
\text { water to } \\
\text { material }\end{array}$ & $\begin{array}{c}\text { Predictive } \\
\text { expansion } \\
\text { ratio (\%) }\end{array}$ & $\begin{array}{c}\text { Experimental } \\
\text { expansion ratio } \\
(\%)\end{array}$ & $\begin{array}{c}\text { Expansion } \\
\text { ratio error }\end{array}$ & $\begin{array}{c}\text { Predictive } \\
\text { compressive } \\
\text { strength (MPa) }\end{array}$ & $\begin{array}{c}\text { Experimental } \\
\text { compressive } \\
\text { strength }(\mathrm{MPa})\end{array}$ & $\begin{array}{c}\text { Compressive } \\
\text { strength error } \\
(\mathrm{MPa})\end{array}$ \\
\hline 1 & 0.51 & 1.37 & 0.6 & 10.7 & 10.3 & 0.4 & 15.1 & 14.8 & 0.2 \\
2 & 0.52 & 1.86 & 0.55 & 10.5 & 10.3 & 0.2 & 15.2 & 15.5 & -0.3 \\
3 & 0.52 & 2 & 0.6 & 10.4 & 10.5 & -0.1 & 15.4 & 15.3 & 15.7 \\
4 & 0.52 & 1.88 & 0.53 & 10.9 & 10.2 & 0.7 & 15.2 & -0.5 \\
5 & 0.53 & 1.05 & 0.6 & 10.4 & 10.7 & -0.3 & 15.6 & 15.2 \\
\hline
\end{tabular}

In summary, in order to ensure the practicability and simplicity of the fieldwork, under the premise of meeting the experimental requirements, the compressive strength is about $15.6 \mathrm{MPa}$, and the expansion ratio is about $10 \%$. The optimised experimental conditions were selected as follows: aluminium powder and quicklime content $0.52 \%$, gypsum content $2 \%$, and the ratio of water to material 0.6 .

\section{Field Application}

The N1103 working face of No. 3 coal seam in Yuwu coal mine of Lu'an Group in Shanxi Province was selected for field testing. The gas content of the coal is high (the gas content of the raw coal is $3.06-23.69 \mathrm{~m}^{3} / \mathrm{t}$ ), and the coal quality is relatively soft $(0.6<f<0.9)$ [41]. With the increase of mining depth, the gas content and pressure of the coal seam increase. At present, it is difficult to mine gas in the working face of Yuwu coal mine. After the hole is formed, the hole section is prone to collapse. It is difficult for the gas extraction pipe to be sent to the designated position in the hole, and it is unable to seal the hole effectively, resulting in low concentration of gas extraction, and the problem of gas outburst cannot be overcome, which brings about significant hidden danger to the safe production of the coal mine.

To investigate the practical application effect of drilling reinforcement seal, in the field test, the method of drilling combination cross was used. A total of 24 experimental boreholes were divided into four groups: A, B, C, and D: each 


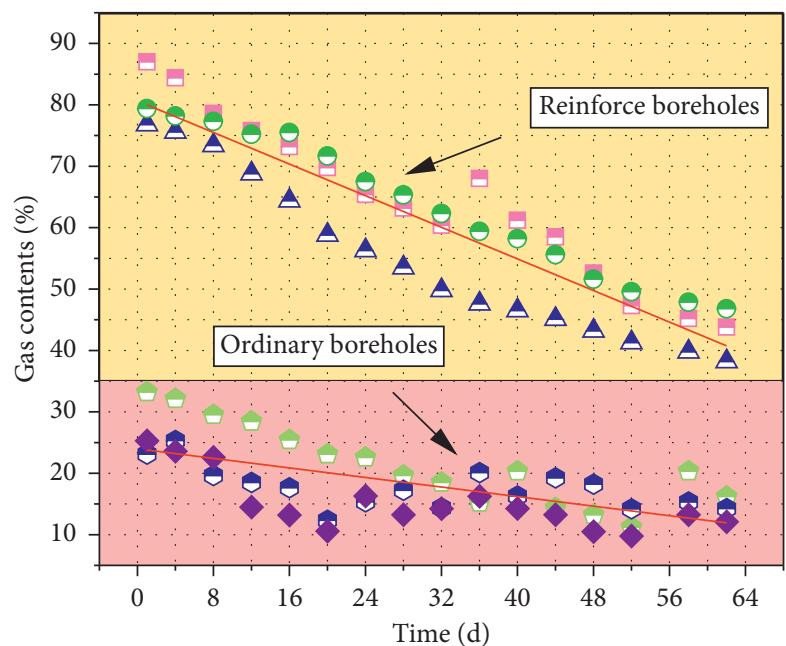

(a)

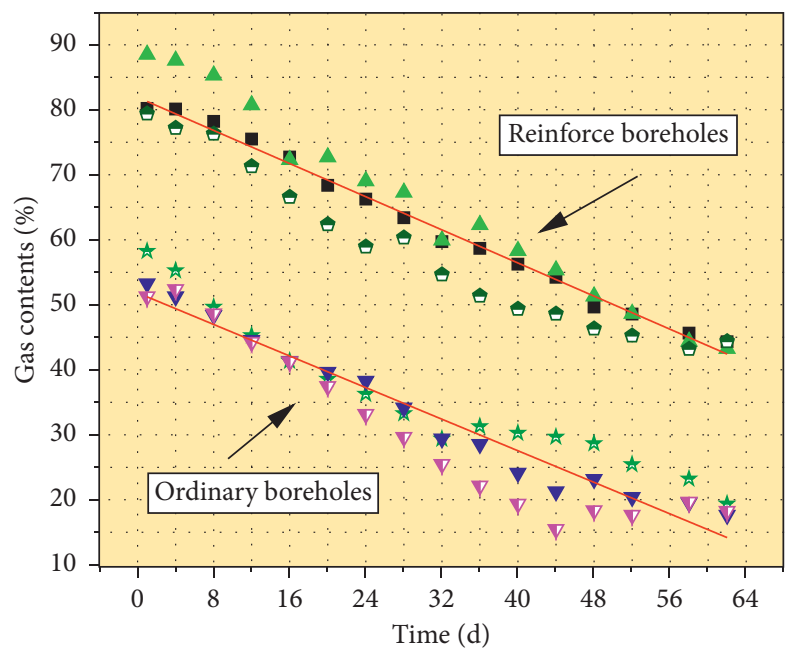

(c)

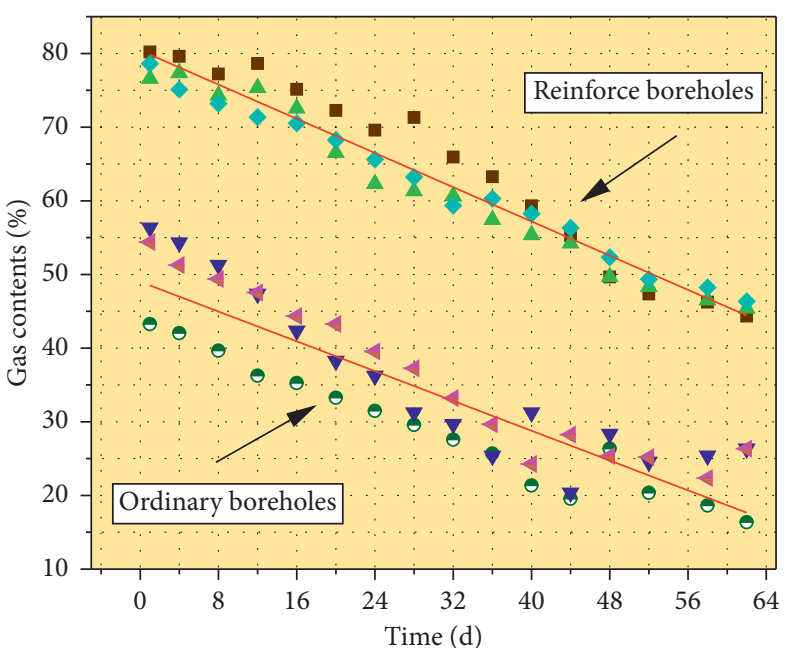

(b)

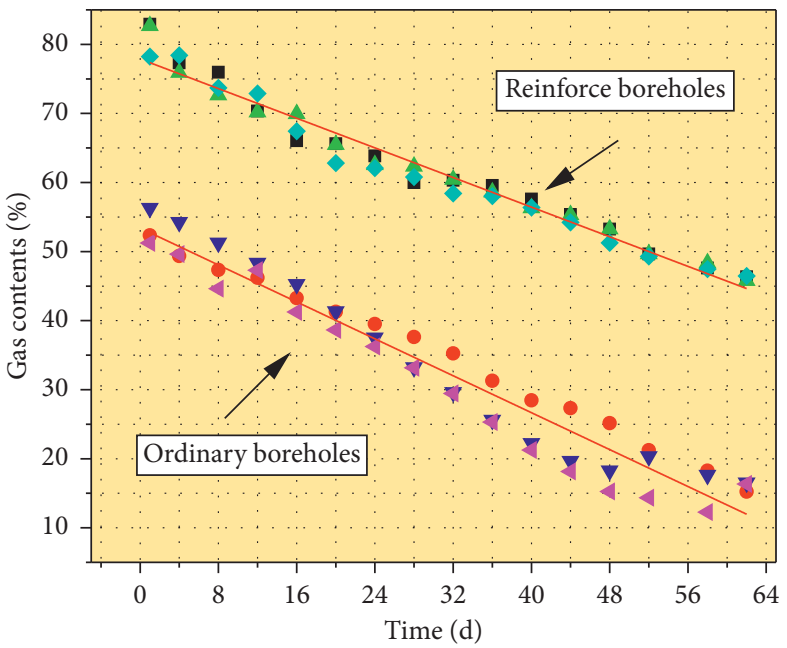

(d)

FIgUre 9: Changes in gas concentration in boreholes with time. (a) Gas content in group A. (b) Gas content in group B. (c) Gas content in group C. (d) Gas content in group D.

group had three optimised boreholes and three ordinary boreholes. After the completion of hole sealing, the gas concentration of 24 holes was monitored for 2 months, and the changes in gas content in the holes are demonstrated in Figure 9.

It can be seen from Figure 9 that the gas concentration of the ordinary borehole without reinforcement is far lower than that of the reinforced borehole in the whole test stage. It can be seen from Figure 9(a) that the gas concentration of ordinary boreholes is below $30 \%$, and the gas concentration of ordinary boreholes in Figures 9(b)-9(d) is better than that in Figure 9(a), but the maximum gas concentration is no more than 60\%; however, observing the gas concentration in the reinforcement boreholes in the above four figures, the gas concentration of the reinforcement boreholes is found to decrease from $80.815 \%$ to $44.62 \%$ after 60 days, and all remain stable.

After 60 days, the average gas concentration of the reinforced hole is $44.62 \%$, the average gas concentration of the unreinforced hole is $17.92 \%$, and the gas concentration of the reinforced hole is 2.48 times that of the unreinforced hole. This is because the collapse of the opening section of the ordinary borehole without reinforcement occurred, and the insufficient feeding position of the gas drainage pipe led to the short length of the sealing section of the borehole and the failure to block the gas flow between the borehole and the roadway, resulting in the low concentration of gas drainage. The results confirm the effectiveness of drilling reinforcement and the practicability of the proposed reinforcement materials.

\section{Conclusion}

To solve the problem of hole sealing (whereby it is easy to lose stability in the sealing section of high gas content, soft coal seams), a new type of drilling reinforcement sealing material was developed. At the same time, the better to combine with the field test in Yuwu coal mine, the following conclusions can be drawn: 
(1) Through the division of the hardness of soft coal seams and coal cutter, the range of compressive strength of reinforcement material was determined. Based on cement-based materials and the mechanism of chemical reaction, the influences of each component of reinforced cement material and the ratio of water to material on its expansivity were studied. A new reinforcement material supplemented with additives such as aluminium powder, quicklime, and gypsum for drilling holes was developed.

(2) The influences of aluminium powder, gypsum, and the ratio of water to material on the expansivity and compressive strength of the solidified material were studied by single-factor experiment, and the influence of the interaction of three factors on the reinforced material was analysed by a response surface method. A reinforced material with an expansion ratio of about $10 \%$ and compressive strength of about $15 \mathrm{MPa}$ was obtained. Verified by experiments, the optimal ratio of key components was obtained as follows: aluminium powder (quicklime), $0.52 \%$; gypsum, $2 \%$; water-to-material ratio, 0.6 .

(3) The better to verify the effectiveness and reliability of the reinforcement material parameters obtained from the physical simulation experiment, Yuwu coal mine was selected as a test bed upon which to validate the effect of the reinforcement material. The gas drainage concentration of the reinforced hole decreased from $80.815 \%$ to $44.62 \%$, which was 2.48 times higher than that of the unreinforced hole, achieving the purpose of hole reinforcement and improving the gas drainage effect.

\section{Data Availability}

The experimental data used to support the findings of this study are available from the corresponding author upon request.

\section{Conflicts of Interest}

The authors declare that they have no conflicts of interest.

\section{Acknowledgments}

This work was financially supported by the National Natural Science Foundation of China (Grant nos. 51974241, 51674189, 51874233, and 51327007).

\section{References}

[1] C. Z. Karacan, "Production history matching to determine reservoir properties of important coal groups in the Upper Pottsville formation, Brookwood and Oak Grove fields, Black Warrior Basin, Alabama," Journal of Natural Gas Science \& Engineering, vol. 10, 2013.

[2] C. Ö. Karacan, "Integration of vertical and in-seam horizontal well production analyses with stochastic geostatistical algorithms to estimate pre-mining methane drainage efficiency from coal seams: Blue Creek seam, Alabama," International Journal of Coal Geology, vol. 114, pp. 96-113, 2013.

[3] K. Morad, "Selected topics in coalbed methane reservoirs," Journal of Natural Gas Science \& Engineering, vol. 8, 2012.

[4] R. C. S. L. C. Zhang, "Controls on hydrogen sulfide formation and techniques for its treatment in the Binchang Xiaozhuang Coal Mine, China," Energy \& Fuels, vol. 39, 2019.

[5] L. Zheng, L. Pan, F. Feng et al., "China's regional disparities in energy consumption: an input-output analysis," Energy, vol. 78, pp. 426-438, 2014.

[6] K. Wang, S. Yu, and W. Zhang, “China's regional energy and environmental efficiency: a DEA window analysis based dynamic evaluation," Mathematical \& Computer Modelling, vol. 58, no. 5-6, pp. 1117-1127, 2013.

[7] V. G. R. C. Govindaraju and C. F. Tang, "The dynamic links between $\mathrm{CO}_{2}$ emissions, economic growth and coal consumption in China and India," Applied Energy, vol. 104, pp. 310-318, 2013.

[8] W. Chaojie, Y. Shengqiang, L. Xiaowei et al., "The correlation between dynamic phenomena of boreholes for outburst prediction and outburst risks during coal roadways driving," Fuel, vol. 10, 2018.

[9] K. Zhang, K. Sun, B. Yu, and R. P. Gamage, "Determination of sealing depth of in-seam boreholes for seam gas drainage based on drilling process of a drifter," Engineering Geology, vol. 210, pp. 115-123, 2016.

[10] S. Kong, Y. Cheng, T. Ren, and H. Liu, “A sequential approach to control gas for the extraction of multi-gassy coal seams from traditional gas well drainage to mining-induced stress relief," Applied Energy, vol. 131, no. 9, pp. 67-78, 2014.

[11] Z. Liu, Y. Cheng, Y. Wang et al., "Experimental investigation of $\mathrm{CO}_{2}$ injection into coal seam reservoir at in-situ stress conditions for enhanced coalbed methane recovery," Fuel, vol. 27, 2019.

[12] Q. Zou, B. Lin, C. Zheng et al., "Novel integrated techniques of drilling-slotting-separation-sealing for enhanced coal bed methane recovery in underground coal mines," Journal of Natural Gas Science and Engineering, vol. 26, pp. 960-973, 2015.

[13] T. Zhang, B. Ruoyu, L. Shugang et al., "Expansion properties and creep tests for a new type of solidified expansive sealing material for gas drainage boreholes in underground mines," Environmental Earth Sciences, vol. 77, no. 12, p. 468, 2018.

[14] X. Xiang, C. Zhai, Y. Xu, X. Yu, and J. Xu, “A flexible gel sealing material and a novel active sealing method for coalbed methane drainage boreholes," Journal of Natural Gas Science and Engineering, vol. 26, pp. 1187-1199, 2015.

[15] X. Chen and Y. Cheng, "Influence of the injected water on gas outburst disasters in coal mine," Natural Hazards, vol. 76, no. 2, pp. 1093-1109, 2015.

[16] C. Zhai, X. Yu, G. Ni et al., "Microscopic properties and sealing performance of new gas drainage drilling sealing material," International Journal of Mining Science and Technology, vol. 4, pp. 16-21, 2013.

[17] C. Zhai, X. Xiang, Q. Zou et al., "Influence factors analysis of a flexible gel sealing material for coal-bed methane drainage boreholes," Environmental Earth Sciences, vol. 75, no. 5, p. 385, 2016.

[18] Z. Chao, C. Jie, L. Shugang et al., "Experimental study comparing the microscopic properties of a new borehole sealing material with ordinary cement grout," Environmental Earth Sciences, vol. 78, no. 5, 2019.

[19] C.-S. Kim and D. Dixon, "Evaluating hydro-mechanical interactions of adjacent clay-based sealing materials," Physics 
and Chemistry of the Earth, Parts $A / B / C$, vol. 65, pp. 98-110, 2013.

[20] Q. Li, B. Lin, and C. Zhai, "A new technique for preventing and controlling coal and gas outburst hazard with pulse hydraulic fracturing: a case study in Yuwu Coal Mine, China," Natural Hazards, vol. 75, no. 3, pp. 2931-2946, 2015.

[21] C. Zhai, L. Qin, S. Liu et al., "Pore structure in coal: pore evolution after cryogenic freezing with cyclic liquid nitrogen injection and its implication on coalbed methane extraction," Energy \& Fuels, vol. 23, 2016.

[22] Z. Wang, Y. Sun, Y. Wang et al., “A coupled model of air leakage in gas drainage and an active support sealing method for improving drainage performance," Fuel, vol. 24, 2019.

[23] N. I. Guan-Hua, B. Q. Lin, C. Zhai et al., "Borehole sealed parameter measurement and analysis of pulsating hydraulic fracturing," Journal of China University of Mining \& Technology, vol. 42, no. 2, pp. 177-182, 2013.

[24] Z. Ge, X. Mei, Y. Lu, J. Tang, and B. Xia, "Optimization and application of sealing material and sealing length for hydraulic fracturing borehole in underground coal mines," Arabian Journal of Geosciences, vol. 8, no. 6, pp. 3477-3490, 2015.

[25] S. S. Hashemi, A. Taheri, and N. Melkoumian, "Shear failure analysis of a shallow depth unsupported borehole drilled through poorly cemented granular rock," Engineering Geology, vol. 183, pp. 39-52, 2014.

[26] S. Erol and B. François, "Efficiency of various grouting materials for borehole heat exchangers," Applied Thermal Engineering, vol. 70, no. 1, pp. 788-799, 2014.

[27] J. H. Wang, "Key technology for fully-mechanized top coal caving with large mining height in extra-thick coal seam," Journal of China Coal Society, vol. 38, no. 12, pp. 67-70, 2013.

[28] K. Giannoukos, M. R. Hall, C. A. Rochelle, A. E. Milodowski, and S. P. Rigby, "Preliminary investigation on the chemical response of cementitious grouts used for borehole sealing of geologically stored $\mathrm{CO}_{2}$," Energy Procedia, vol. 59, pp. 174181, 2014.

[29] J. Xiao, Z. Li, Q. Xie et al., "Effect of strain rate on compressive behaviour of high-strength concrete after exposure to elevated temperatures," Fire Safety Journal, vol. 83, 2016.

[30] W. S. Ansari and J. Chang, "Influence of fine cement sand paste in preparation of cementitious materials," Construction and Building Materials, vol. 23, p. 230, 2020.

[31] Y. Liu, B. S. Leong, Z.-T. Hu, and E.-H. Yang, “Autoclaved aerated concrete incorporating waste aluminum dust as foaming agent," Construction and Building Materials, vol. 148, pp. 140-147, 2017.

[32] L. W. Mo, Y. Deng, A. Q. Lu, and M. Deng, "Preparation of $\mathrm{MgO}$ - and $\mathrm{CaO}$ - bearing expansive agent used for cementbased materials," Key Engineering Materials, vol. 539, pp. 211-214, 2013.

[33] P. Yan and Y. You, "Studies on the binder of fly ash-fluorgypsum-cement," Cement and Concrete Research, vol. 28, no. 1, pp. 135-140, 1998.

[34] J. Zhou, K. Zheng, Z. Liu et al., "Use of $\gamma-\mathrm{Al}_{2} \mathrm{O}_{3}$ to prevent alkali-silica reaction by altering solid and aqueous compositions of hydrated cement paste," Cement and Concrete Research, vol. 124, 2019.

[35] L. Qin, C. Zhai, S. Liu et al., "Factors controlling the mechanical properties degradation and permeability of coal subjected to liquid nitrogen freeze-thaw," Scientific Reports, vol. 7, no. 1, p. 3675, 2017.

[36] M. Sadique, H. Al-Nageim, W. Atherton, L. Seton, and N. Dempster, "Mechano-chemical activation of high-Ca fly ash by cement free blending and gypsum aided grinding,"
Construction and Building Materials, vol. 43, pp. 480-489, 2013.

[37] T. Liu, B. Lin, C. Zheng, Q. Zou, C. Zhu, and F. Yan, "Influence of coupled effect among flaw parameters on strength characteristic of precracked specimen: application of response surface methodology and fractal method," Journal of Natural Gas Science and Engineering, vol. 26, pp. 857-866, 2015.

[38] K. Q. Tu, L. J. Zhang, Z. S. Du et al., "Pressure retaining sealing holes technique of PD material," Safety in Coal Mines, vol. 34, 2012.

[39] H. Akgün and M. K. Ko Kar, "Evaluation of a sand bentonite mixture as a shaft/borehole sealing material," Applied Clay Science, vol. 32, Article ID S200156742, 2018.

[40] J.-Y. Liu, Z.-S. Qiu, and W. A. Huang, "Novel latex particles and aluminum complexes as potential shale stabilizers in water-based drilling fluids," Journal of Petroleum Science and Engineering, vol. 135, pp. 433-441, 2015.

[41] D. Y. Guo, J. N. Li, and Y. K. Wang, "Early-warning model of coal and gas outburst based on the stick-slip and catastrophe theory," Journal of University of Science \& Technology Beijing, vol. 35, no. 11, pp. 1407-1412, 2013. 